\title{
Plasma Potential Measurements in the Discharge Channel of a 6-kW Hall Thruster
}

\author{
Bryan M. Reid ${ }^{1}$ and Alec D. Gallimore ${ }^{2}$ \\ University of Michigan, Ann Arbor, MI 48109
}

\begin{abstract}
In an effort to understand the role of neutral flow dynamics in the operation of Hall thrusters, a floating emissive probe was used to measure the plasma potential, electric field, and electron temperature in the discharge channel of a 6-kW Hall thruster operating at 300 $\mathrm{V}$ and anode flow rates of 10,20 , and $30 \mathrm{mg} / \mathrm{s}$. To isolate the effect of propellant flow rate, the cathode flow fraction and magnetic field topology were held constant while varying magnetic field strength to minimize discharge current while maximizing thrust. The probe was inserted and removed from the discharge channel by a high-speed positioning system at nine radial locations. The plasma potential profiles showed little variation in the radial direction, leading to negligible radial electric field and ion focusing towards channel centerline. The peak axial electric field occurred near the exit plane, moving downstream 3$5 \%$ of the channel length for each addition of $10 \mathrm{mg} / \mathrm{s}$. The electron temperature calculated by the difference in plasma and floating potentials agreed well with Langmuir probe measurements at $10 \mathrm{mg} / \mathrm{s}$, but results at 20 and $30 \mathrm{mg} / \mathrm{s}$ displayed poor agreement. The Langmuir probe peak electron temperature decreased by about $5 \mathrm{eV}$ and moved downstream 3-5\% of the channel length for each addition of $10 \mathrm{mg} / \mathrm{s}$. The results indicate a strong dependence of peak plasma property magnitude and location on neutral collisions.
\end{abstract}

\section{Nomenclature}

$\begin{array}{lll}b & = & \text { discharge channel width } \\ e & = & \text { electron charge, } \mathrm{C} \\ E_{z} & = & \text { axial electric field, } \mathrm{V} / \mathrm{mm} \\ k_{B} & = & \text { Boltzmann's constant, } \mathrm{J} / \mathrm{K} \\ L_{c} & = & \text { discharge channel length } \\ m_{e} & = & \text { electron mass, } \mathrm{kg} \\ M_{i} & = & \text { ion mass, } \mathrm{kg} \\ T_{e} & = & \text { electron temperature, } \mathrm{eV} \\ V_{a c c e l} & = & \text { acceleration potential, } \mathrm{V} \\ V_{d} & = & \text { discharge voltage, } \mathrm{V} \\ V_{f} & = & \text { floating potential, } \mathrm{V} \\ V_{p} & = & \text { plasma potential, } \mathrm{V} \\ Z & = & \text { axial location, measured from anode } \\ \eta_{v} & = & \text { voltage utilization efficiency }\end{array}$

\section{Introduction}

$\mathrm{H}$ ALL thrusters have become an integral part of the satellite propulsion architecture. Identifying the ability of Hall thrusters to operate beyond their nominal operation conditions is important for the future viability of the technology. The Hall thruster simulation community is also interested in the behavior across a wide range of operating conditions, using experimental observations to validate and improve existing modeling capability. To understand how thrusters operate at off nominal conditions, the location, size, and intensity of the ionization and

\footnotetext{
${ }^{1} \mathrm{Ph}$. D. Candidate, Plasmadynamics and Electric Propulsion Laboratory, reidb@umich.edu, and AIAA student member.

${ }^{2}$ Arthur F. Thurnau Professor of Aerospace Engineering and Director of the Plasmadynamics and Electric Propulsion Laboratory, alec.gallimore@umich.edu, and AIAA senior member.
} 
acceleration regions must determined. The best method of characterizing these plasma properties is with internal plasma diagnostics, especially electrostatic probes. In particular, floating emissive probes provide a relatively accurate measurement the plasma potential in the discharge channel. Previous studies have shown the ability of these probes to accurately measure the plasma potential and survive the harsh environment that exists in the discharge channel of a Hall thruster [1,2]. To isolate the effect of neutral flow rate, the magnetic field shape, cathode flow fraction, and discharge voltage were kept constant while varying anode flow rate. The 6-kW thruster was designed for nominal operation at $300 \mathrm{~V}$ and $20 \mathrm{mg} / \mathrm{s}$, but during this study it was operated at discharge powers ranging from approximately 3 to $10 \mathrm{~kW}$, corresponding to $300 \mathrm{~V}$ at 10,20 , and $30 \mathrm{mg} / \mathrm{s}$.

The experimental apparatus used in this study are covered along with a brief theory of probe operation. Results are shown for plasma potential, axial electric field, and electron temperature based on emissive and Langmuir probes throughout the measurement domain. The discussion section considers the linear increase in electron temperature with plasma potential that has been suggested in the literature [3], followed by analysis of the peak property locations and their dependence on mass flow rate.

\section{Experimental Apparatus}

\section{A. Vacuum Facility}

Experiments were performed in the Large Vacuum Test Facility (LVTF) at the University of Michigan Plasmadynamics and Electric Propulsion Laboratory (PEPL). The LVTF is a 6-meter-diameter, 9-meter-long, cylindrical, stainless steel vacuum chamber. Pumping was provided by seven single-stage CVI model TM-1200 cryo-pumps and liquid nitrogen shrouds, with a nominal pumping speed of 240,000 1/s on xenon. Facility pressure was monitored by two hot-cathode ionization gauges, and base pressure was approximately $2.3 \times 10^{-7}$ torr. The facility pressure during thruster operation at $22 \mathrm{mg} / \mathrm{s}$ total xenon flow rate was approximately $1.3 \times 10^{-5}$ torr, corrected for xenon.

\section{B. Hall Thruster}

Experiments were performed using a 6-kW laboratory model Hall thruster that has an approximate throttling range of $100-600 \mathrm{mN}$ and $1000-3000 \mathrm{~s}$ specific impulse [4-7]. The thruster was equipped with a center-mounted $\mathrm{LaB}_{6}$ hollow cathode that was operated at $7 \%$ of the anode mass flow rate. Research-grade xenon propellant ( $99.999 \%$ pure) was supplied to the anode and cathode by separate commercially-available flow meters and controllers, having an accuracy of $\pm 1 \%$ of full scale. The system was calibrated using a constant volume method including the effects of compressibility [8]. The thruster discharge was sustained by a $100 \mathrm{~kW}$ power supply that provided a maximum output of $1000 \mathrm{~V}$ at $100 \mathrm{~A}$. The thruster was positioned so that it was elevated to chamber centerline, allowing the plume to expand for approximately four meters along the chamber axis.

\section{High-speed Positioning System}

The emissive probe was inserted and removed from the thruster discharge channel using the High-speed Axial Reciprocating Probe (HARP) at PEPL. The HARP has an acceleration and velocity capability of approximately 70 $\mathrm{m} / \mathrm{s}^{2}$ (7 g's) and $2.5 \mathrm{~m} / \mathrm{s}$, respectively [9]. For this experiment, the HARP was operated at $1.5 \mathrm{~m} / \mathrm{s}$, resulting in a residence time within the discharge channel of less than $100 \mathrm{~ms}$. The residence time was minimized to reduce the heat load on the probe, potentially extending its operational lifetime.

To reduce the effects of the vacuum chamber compression during initial evacuation, the HARP and thruster translation stage were connected by a steel support structure. The HARP was fixed to the support structure downstream of the thruster to dampen oscillations that are produced by the actuation of the probe arm. The thruster was mounted to a $1.5-\mathrm{m}$-long translation stage that adjusted the radial location of the probe within the discharge channel. 

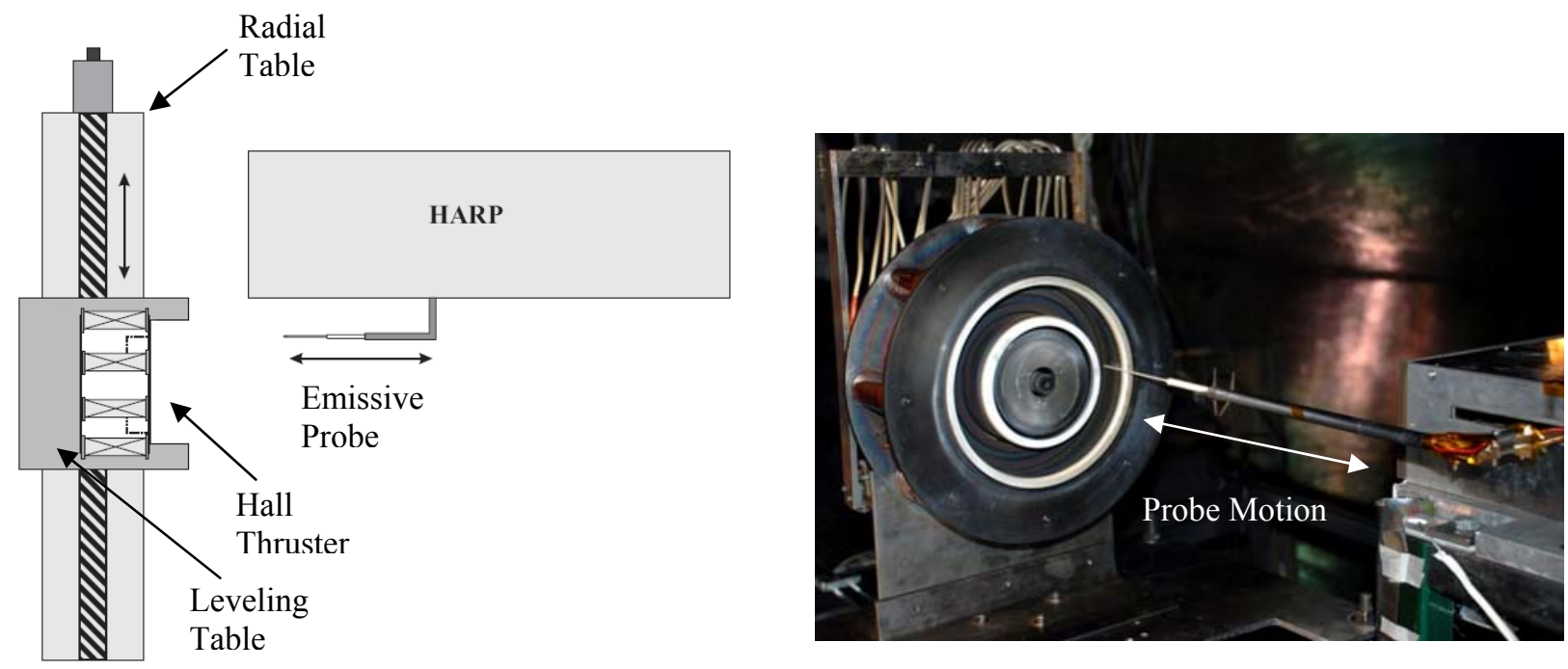

Figure 1. Schematic of thruster and probe positioning systems and photograph of probe insertion into thruster discharge channel.

\section{Floating Emissive Probe}

The floating emissive probe has significant heritage for measuring the plasma potential in the discharge channel of Hall thrusters [1, 2, 10-12]. The probe design, operation, and analysis methods are based on the work of Haas [1].

\section{Principles of Operation}

The emissive probe relies on a hot filament that produces thermionic emission of electrons. When the current density provided by the filament approaches the local plasma current density, the probe floats at the local plasma potential. While the probe emission is below this critical value, the probe surface is negative with respect to the plasma, and emitted electrons are lost to the surrounding plasma. As emission is increased, more electrons are lost per unit time, necessitating an increase in probe potential. As the emission approaches the critical current density, the probe reaches the plasma potential and emitted electrons are returned to the probe.

The ideal behavior of an emissive probe is complicated by the presence of space-charge limited emission, which leads to a double sheath near the probe surface. The double sheath creates a potential well that reflects some of the emitted electrons to the probe. Since these electrons are not reflected by the plasma, the probe will tend to float below the plasma potential. This effect is only alleviated when the emitted electron temperature is equal to the plasma electron temperature, leading to a symmetric double sheath [13]. This condition is rarely achieved in the Hall thruster plume and discharge channel since the emitted electrons are typically $<1 \mathrm{eV}$, whereas the plasma electrons range from 5 to $30 \mathrm{eV}$ at nominal conditions.

To account for the uncertainty introduced by the double sheath, space-charge limited emission, and electron temperature mismatch, the plasma potential measured by the emissive probe must be corrected by $0.6 \mathrm{Te}[14,15]$. The uncertainty associated with the plasma potential correction is estimated at $0.9 \mathrm{Te}[15,16]$, which is in addition to the uncertainty introduced by the voltage drop across the filament. To reduce magnetic field effects, the probe was oriented so that the plane of the filament loop is normal to the thruster radial direction. Although the effect is expected to be relatively small, the effect of magnetic field was not explicitly accounted for.

\section{Probe Design}

The floating emissive probe was used to measure the plasma potential in the thruster discharge channel from 3 to $10 \mathrm{~kW}$. As the discharge power increases, the heat load to the probe increases, ultimately leading to probe failure when the ceramic surface temperature reaches a significant fraction of its melting temperature. This critical power limit was reached at $6 \mathrm{~kW}(300 \mathrm{~V}, 20 \mathrm{mg} / \mathrm{s})$ for an alumina probe body based on the design implemented by Haas [1] and Linnell [2]. To alleviate the probe failure mechanism associated with elevated thruster discharge power, a unique probe design had to be implemented. In particular, new materials were investigated for use as the probe body, summarized in Table 1. The only viable material options were zirconium oxide and boron nitride due to the necessity for higher operating temperature. Although zirconium oxide has a high operating temperature, high strength, and good thermal shock properties, it becomes conductive at temperatures above $870 \mathrm{~K}$, well below the 
expected exposure temperature of $>2300 \mathrm{~K}$. Boron nitride is the superior material choice when considering the high maximum use temperature (55\% higher than alumina), high thermal conductivity ( $100 \%$ higher than alumina), high dielectric strength (375\% higher than alumina), and low thermal expansion (14 times lower than alumina). The only potential weakness for boron nitride is the low elastic modulus (27 times lower than alumina), which indicates that the material is very fragile.

Table 1. Properties of candidate dielectric materials for use in probe construction.

\begin{tabular}{|c|c|c|c|c|c|}
\hline Material & $\begin{array}{l}\text { Maximum } \\
\text { Temperature, } \mathrm{K} \\
\end{array}$ & $\begin{array}{l}\text { Thermal } \\
\text { Conductivity, W/m-K }\end{array}$ & $\begin{array}{l}\text { Coefficient of Thermal } \\
\text { Expansion, } 10^{-6} \mathrm{~m} / \mathrm{m}-\mathrm{K}\end{array}$ & $\begin{array}{l}\text { Dielectric } \\
\text { Strength, } \mathrm{kV} / \mathrm{mm}\end{array}$ & $\begin{array}{l}\text { Elastic } \\
\text { Modulus, GPa } \\
\end{array}$ \\
\hline Macor & 1300 & 2 & 12.6 & 40 & 67 \\
\hline $\begin{array}{l}\text { Silicon Carbide } \\
(\mathrm{SiC})\end{array}$ & 1920 & 120 & 4 & -- & 410 \\
\hline $\begin{array}{l}\text { Mullite } \\
\left(3 \mathrm{Al}_{2} \mathrm{O}_{3} 2 \mathrm{SiO}_{2}\right)\end{array}$ & 1920 & 6 & 5.4 & 10 & 151 \\
\hline $\begin{array}{l}\text { Aluminum Oxide } \\
99.5 \%\left(\mathrm{Al}_{2} \mathrm{O}_{3}\right)\end{array}$ & 2200 & 35 & 8.4 & 17 & 375 \\
\hline $\begin{array}{l}\text { Zirconium Oxide } \\
\left(\mathrm{ZrO}_{2}\right)\end{array}$ & 2670 & 2 & 10.3 & 10 & 200 \\
\hline $\begin{array}{l}\text { Boron Nitride } \\
\text { grade XP (BN) }\end{array}$ & 3270 & 71 & 0.6 & 80 & 14 \\
\hline
\end{tabular}

The approximate required surface temperature of the filament can be estimated by considering the necessary surface emission from the Richardson-Dushman equation to balance the electron density near the probe [2]. The probe was expected to encounter a range of peak densities and temperatures from 0.1 to $1 \times 10^{13} \mathrm{~cm}^{-3}$ and 15 to 30 $\mathrm{eV}$, respectively. This range of conditions requires that the emissive probe provide an emissive capability of approximately $10-170 \mathrm{~A} / \mathrm{cm}^{2}$. Covering this range is not possible with tungsten since the estimated surface temperature would need to go from 3000 to $3500 \mathrm{~K}$, dangerously close to the melting point of $3700 \mathrm{~K}$. However, $1 \%$ thoriated tungsten can produce the required range of emission with surface temperatures from 2200 to $2700 \mathrm{~K}$, offering a desirable safety factor that prevents the probe from melting. The maximum emission current required to neutralize the probe sheath remained on the order of $10 \mathrm{~mA}$, which is at least three orders of magnitude less than the thruster discharge current. This indicates that the probe emission can be considered as a negligible contribution to the thruster discharge.

The emissive probe was constructed using three major components for the body; a 1.5 -mm-diameter, doublebore, alumina tube, telescoped inside a 6.4-mm-diameter alumina tube, capped by a graduated boron nitride shroud as shown in Figure 2. The boron nitride shroud was split into three sections with diameters of 3, 5, and $6.4 \mathrm{~mm}$, each of which was 35, 8, and $8 \mathrm{~mm}$ long, respectively. The filament loop was based on the design of Haas [17], and was composed of $0.127-\mathrm{mm}$-diameter $1 \%$ thoriated tungsten wire that bent with a radius of curvature of $0.5 \mathrm{~mm}$. The total exposed length of the filament wire was approximately $3.5 \mathrm{~mm}$, resulting in an emission surface area of approximately $1.5 \times 10^{-3} \mathrm{~cm}^{2}$. 


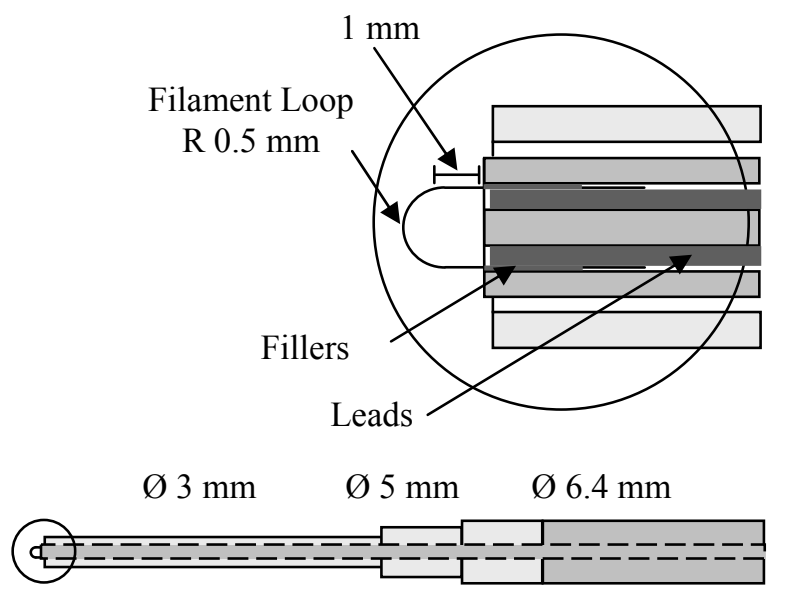

$\begin{array}{lll}\square & \text { Boron Nitride } \\ \square & \text { Tungsten } \\ & \text { Thoriated Tungsten }\end{array}$

Figure 2. Schematic of probe design and construction (not to scale).

\section{Data Acquisition and Probe Measurement Circuit}

The data acquisition (DAQ) system recorded the probe position, filament high-potential, filament low-potential, thruster discharge current, and thruster cathode potential at $83 \mathrm{kHz}$ per channel. This resulted in a distinct plasma potential measurement every $0.04 \% \mathrm{Lc}$. The sampling frequency was sufficiently high to capture the breathing mode oscillations that range from 10 to $40 \mathrm{kHz}$.

The floating emissive probe circuit consists of the emissive probe, a floating DC power supply capable of supplying enough current to heat the filament (3-5 A), and two voltage divider circuits. Each voltage divider circuit was composed of two high-impedance thin-film resistors, and the voltage drop across the minor resistor was measured with a voltage following operational amplifier that had a minimum bandwidth of $20 \mathrm{kHz}$. The voltage measurement circuits were enclosed in a grounded case and located inside the chamber. The output signal was connected to the DAQ by $50 \Omega \mathrm{BNC}$ cables and feed throughs, and the entire system was calibrated at DC, displaying excellent linearity. A schematic of the probe circuit is shown in Figure 3.

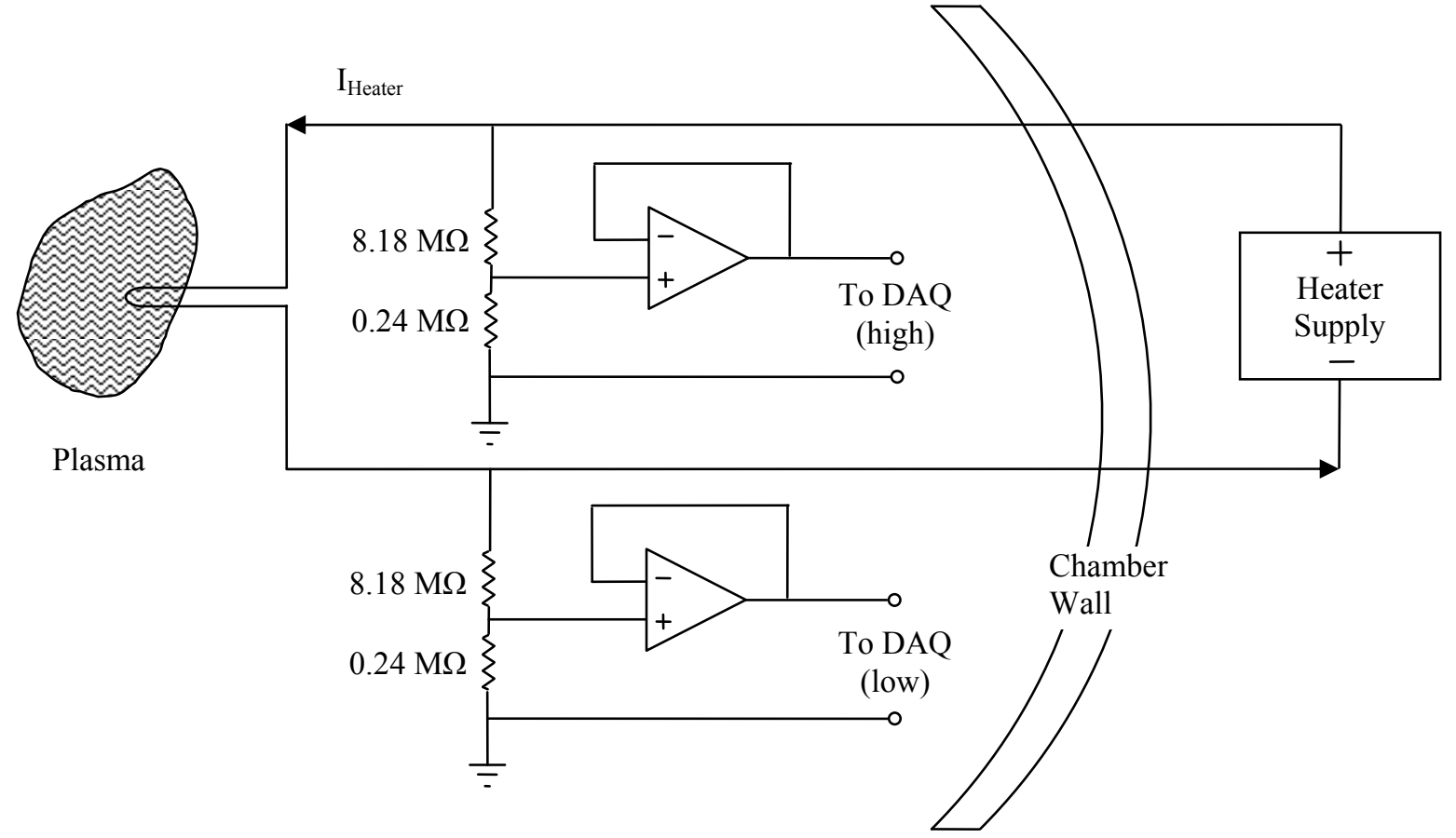

Figure 3. Schematic of emissive probe voltage measurement circuit and heater supply.

American Institute of Aeronautics and Astronautics 
Previous measurements $[1,2]$ reported the potential on the high side of the probe, reduced by one-half of the voltage drop across the filament. This was a good approximation since the voltage drop across the filament in those experiments did not vary by more than $5 \mathrm{~V}$. However, a more rigorous measurement is achieved by recording the voltage on both sides of the filament. In addition to providing a more accurate measurement of the local plasma potential, measuring both sides of the filament also provides a diagnostic tool to monitor the emissive probe emission saturation. For a properly saturated emissive probe, the voltage drop will remain approximately constant as the probe is passed into the out of the thruster. The nearly constant voltage drop results in a percent voltage drop, $\left(\mathrm{V}_{\text {high }}-\mathrm{Vl}_{\mathrm{ow}}\right) / \mathrm{V}_{\mathrm{p}}$ that monotonically decreases until reaching the anode due to the monotonic increase in plasma potential. Hence, if the percent voltage drop has a significant increase near the location of the Hall current, then the probe is not properly saturated since it is requires additional heating from the impact of high-energy electrons to float at the local plasma potential. A comparison of the percent voltage drop for a fully saturated and partially saturated emissive probe is shown in Figure 4 along channel centerline at $300 \mathrm{~V}, 10 \mathrm{mg} / \mathrm{s}$.

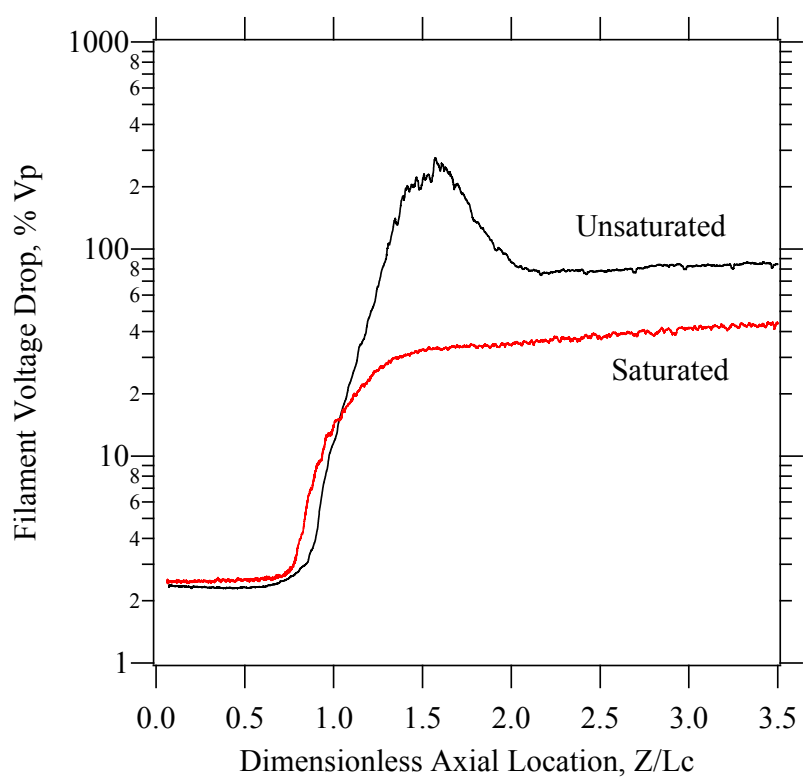

Figure 4. Emissive probe filament voltage drop along channel centerline.

\section{Measurement Domain}

The measurement domain was normalized by the channel length, Lc, and channel width, $b$. The anode was located at $0 \% \mathrm{Lc}$, the channel exit as $100 \% \mathrm{Lc}$, the inner wall was located at $0 \% \mathrm{~b}$, and the outer wall was located at $100 \%$ b. Data were taken at nine radial locations spaced $8 \%$ of the channel width apart, as shown in Figure 5. Although data were sampled every $0.045 \% \mathrm{Lc}$ in the axial direction, results are reported every $0.25 \%$ Lc due to the finite probe size. This averaging removed the high-frequency oscillations $\left(10^{4} \mathrm{~Hz}\right)$ that are characteristic of Hall thruster discharges, resulting in a time-averaged measurement of the local plasma potential. 


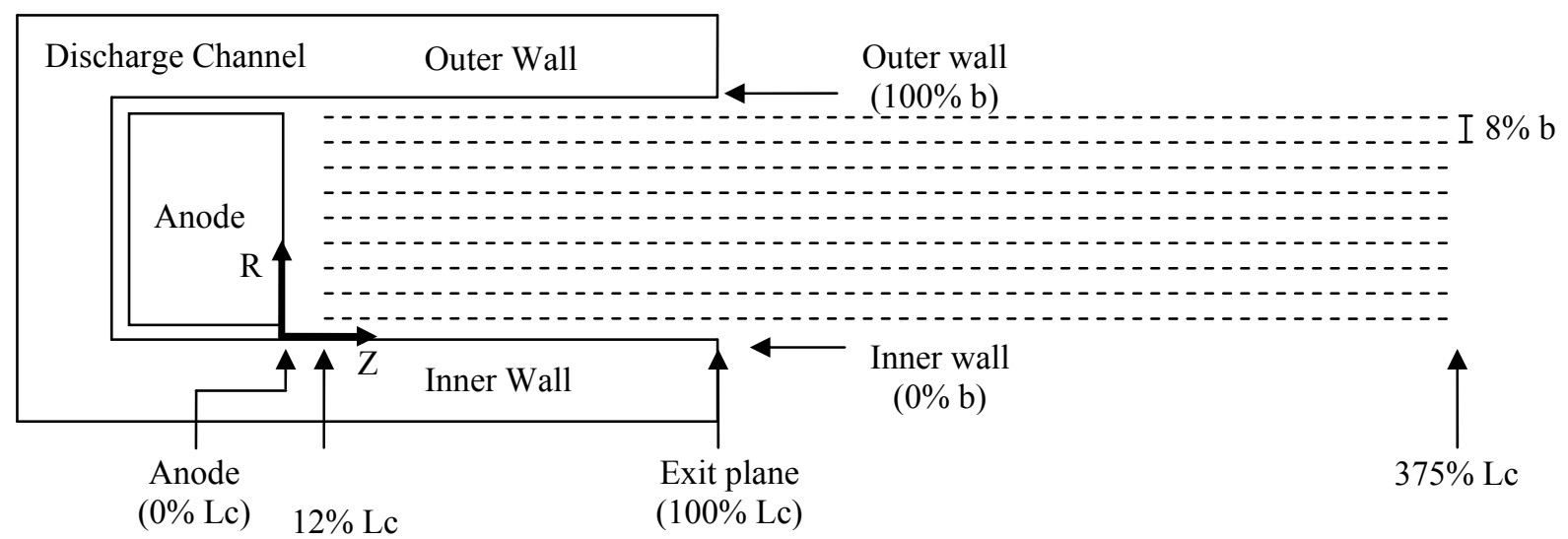

Figure 5. Schematic of measurement domain (not to scale).

\section{Probe-Induced Thruster Perturbations}

Probe-induced thruster perturbations were characterized by examining the discharge current and voltage during probe insertion and removal from the thruster channel. The probe position, plasma potential, discharge voltage, and discharge current are shown in Figure 6 for $300 \mathrm{~V}, 10 \mathrm{mg} / \mathrm{s}$. Nominal discharge current oscillations were about 40\%, reaching a maximum between $50-60 \%$. These data indicate that the probe-induced perturbations were below $20 \%$, an acceptable value that is consistent with previous work $[1,2,10]$.

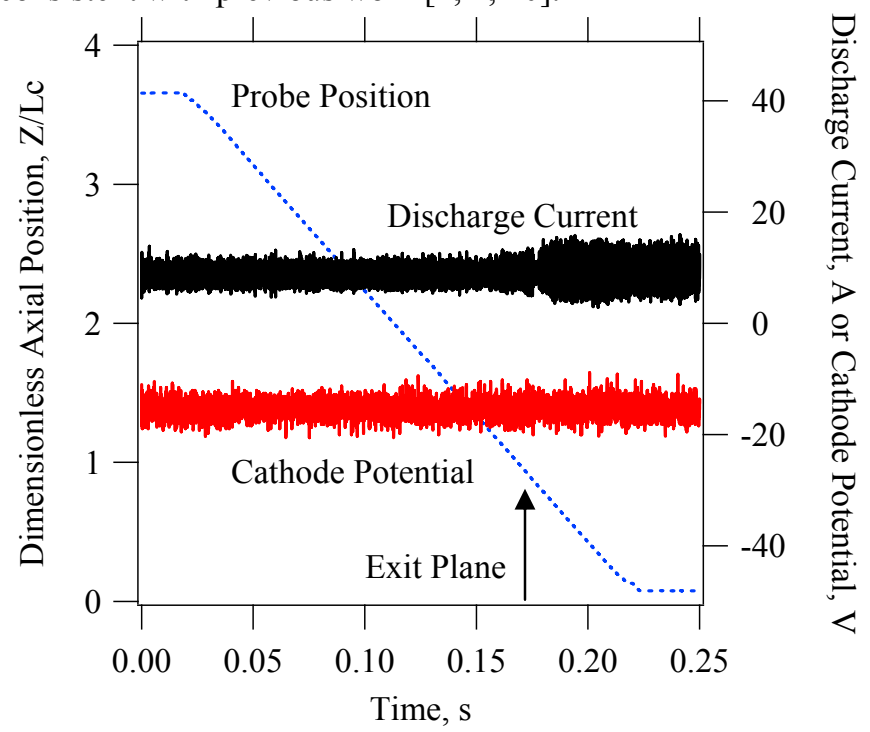

Figure 6. Probe induced perturbations of discharge current and cathode potential.

\section{Instantaneous Plasma Potential}

High-frequency (10-40 kHz) discharge current oscillations, often referred to as the "breathing mode instability," were observed during all probe measurements. Fluctuations in the plasma potential were correlated to the discharge current oscillations which ranged from 20 to $25 \mathrm{kHz}$. The distinct correlation between peak plasma potential and peak discharge current can be seen in Figure 7 for $300 \mathrm{~V}, 10 \mathrm{mg} / \mathrm{s}$. The plasma potential had a phase lag of 30-40 $\mu \mathrm{s}$, likely attributed to the sampling locations of both measurements. Another lower frequency discharge oscillation (1-5 $\mathrm{kHz}$ ), often referred to as the "spoke mode instability," was observed in the discharge current and plasma potential measurements. Although instantaneous plasma potential measurements were recorded, the time-averaged results are used throughout this paper. 


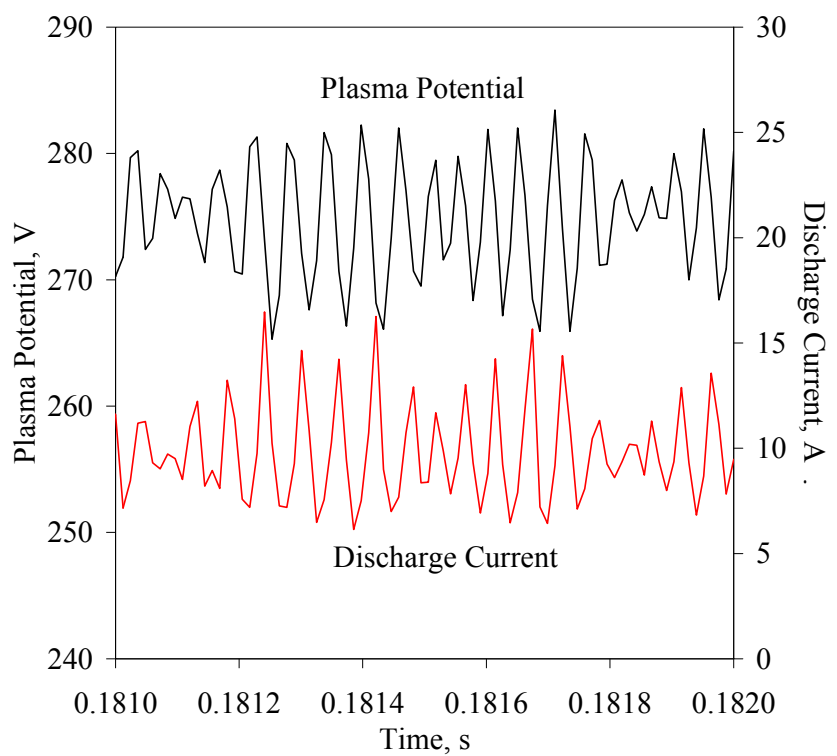

Figure 7. Plasma potential and discharge current oscillations.

\section{Results}

The plasma potential was measured in the discharge channel at $300 \mathrm{~V}$ at 10,20 , and $30 \mathrm{mg} / \mathrm{s}$. The thruster operating conditions were optimized by maintaining a constant cathode flow fraction of $7 \%$ and constant magnetic field shape, while varying the magnetic field strength to maintain thruster stability, minimize discharge current, and maximize thrust.

Due to the intense probe heating at the $300 \mathrm{~V}, 30 \mathrm{mg} / \mathrm{s}$ operating condition $(\sim 10 \mathrm{~kW})$, the probe filament was unable to survive repeated sweeps into the thruster. The only reliable data was collected at thruster centerline, and was used across the entire channel for calculation of corrected plasma potential and axial electric field. The corrected plasma potential was used across the channel to allow calculation of the electron temperature. All plasma potential measurements are referenced to facility ground.

\section{A. Electron Temperature}

The electron temperature was calculated by using the potential difference between the plasma and floating potentials as shown in Equation 1

$$
V_{p}-V_{f}=-\frac{k_{B} T_{e}}{e} \ln \left(0.605 \sqrt{\frac{2 \pi m_{e}}{M_{i}}}\right) .
$$

The uncertainty in this temperature calculation was estimated as $\pm 17 \%$ [10]. This calculation required knowledge of the plasma potential from the floating emissive probe and the floating potential, which was taken from the Langmuir probe measurements in a companion experiment [18]. This equation was derived based on the assumption that the plasma is quiescent and characterized by Maxwellian electrons with temperature much greater than the ion temperature, and negligible effects due to orbital motion [19]. These assumptions were not necessarily valid throughout the entire measurement domain; however the electron temperature from this calculation serves as a reasonable comparison of the electron temperature determined by the Langmuir probe. The electron temperature calculated with Langmuir and emissive probes at $300 \mathrm{~V}, 10,20$, and $30 \mathrm{mg} / \mathrm{s}$ are shown the first and second rows of Figure 11, respectively. The emissive probe electron temperature was much more uniform across the channel, more widespread along the channel, and increased in peak value with increased mass flow rate. This trend opposed that of the Langmuir probe, which was characterized by decrease in peak temperature with increased flow rate. The

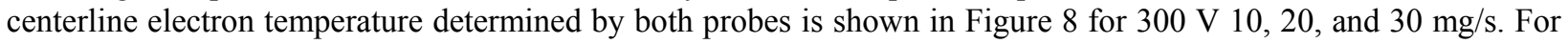
the Langmuir probe, the centerline electron temperature peaked at approximately 38,35 , and $25 \mathrm{eV}$ at 10, 20, and 30 $\mathrm{mg} / \mathrm{s}$, respectively. For the emissive probe, the electron temperature peaks at approximately 28,38 , and $42 \mathrm{eV}$ at 10 , 20 , and $30 \mathrm{mg} / \mathrm{s}$, respectively. In addition to the variation in peak electron temperature for the Langmuir and emissive probe calculations, the peak location moved downstream with each addition of anode flow rate. The peak 
electron temperature occurred respectively at 10,20 , and $30 \mathrm{mg} / \mathrm{s}$ at locations of 86,90 , and $98 \% \mathrm{Lc}$ for the Langmuir probe, and 79,90 , and $93 \% \mathrm{Lc}$ for the emissive probe.

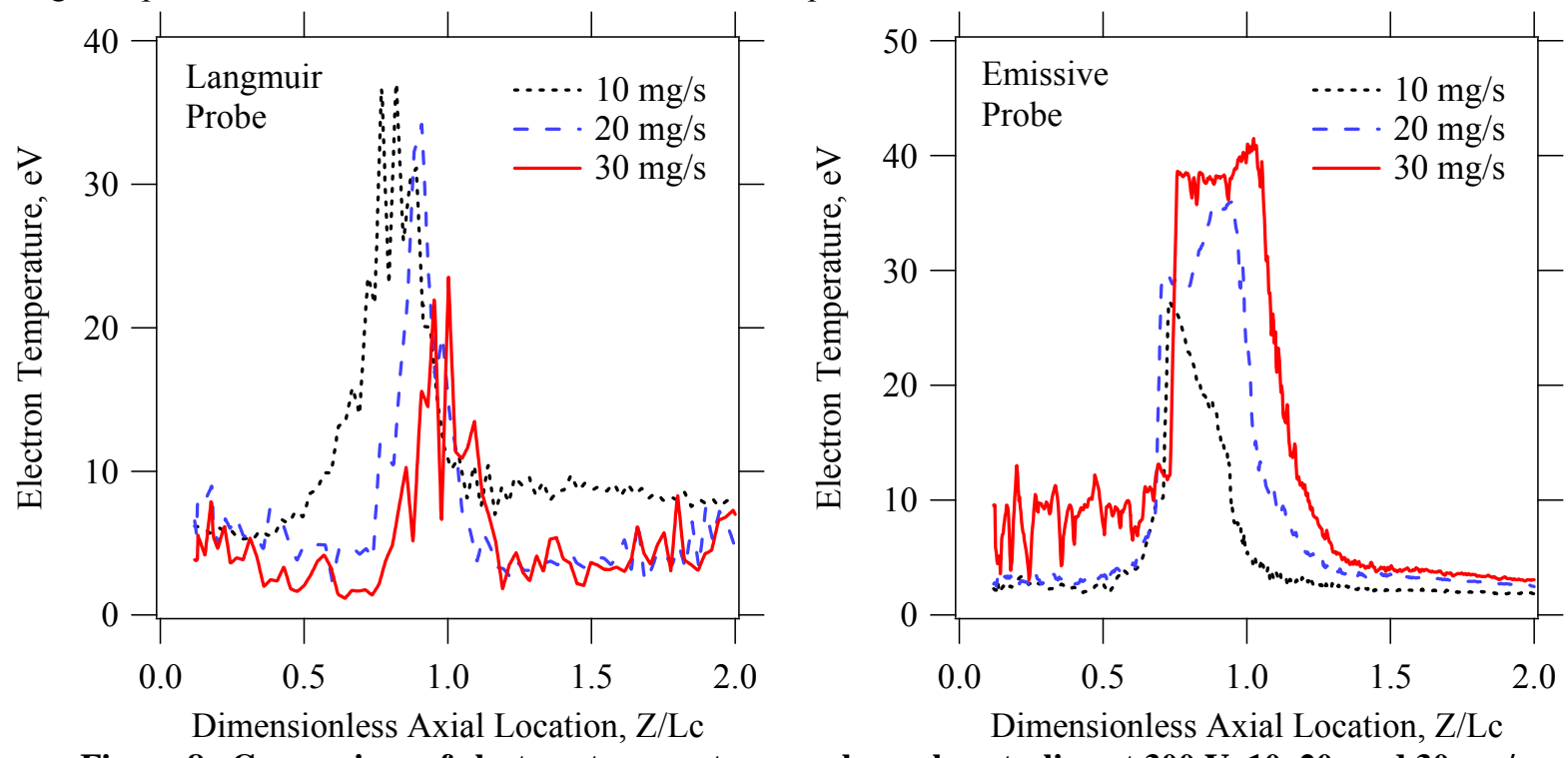

Figure 8. Comparison of electron temperature on channel centerline at $300 \mathrm{~V}, 10,20$, and $30 \mathrm{mg} / \mathrm{s}$.

\section{B. Plasma Potential}

Although the two electron temperature measurement methods (Langmuir and emissive) showed reasonable agreement, all plasma potential measurements are corrected using the electron temperature measured by the Langmuir probe in Ref. [18]. The corrected plasma potential throughout the measurement domain for $300 \mathrm{~V}$ at 10 , 20 , and $30 \mathrm{mg} / \mathrm{s}$ is shown in the third row of Figure 11. The plasma potential was highly uniform across the channel at all three operating conditions.

The centerline electron temperature and plasma potential before and after correction by the electron temperature are shown in Figure 9a for $300 \mathrm{~V}, 10 \mathrm{mg} / \mathrm{s}$. The electron temperature correction did not have a significant impact on the profile of the plasma potential. The corrected plasma potential is compared on channel centerline in Figure $9 \mathrm{~b}$ for $300 \mathrm{~V}, 10,20$, and $30 \mathrm{mg} / \mathrm{s}$. This comparison indicated an increase in the plasma potential slope (electric field) and axial displacement of the peak acceleration location as the mass flow rate was increased.
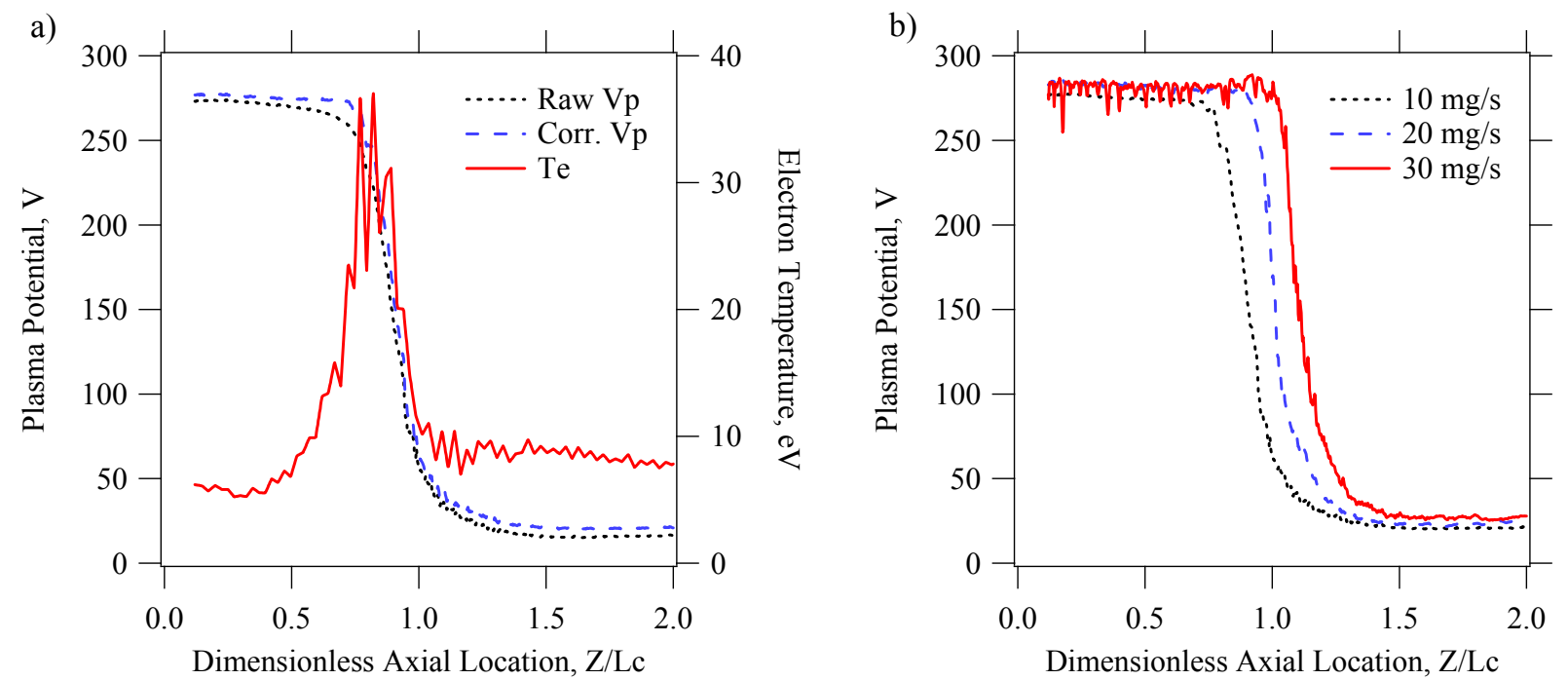

Figure 9. a) Comparison of pre- and post-corrected plasma potentials, including electron temperature at 300 $\mathrm{V}, 10 \mathrm{mg} / \mathrm{s}$, and b) comparison of plasma potential on channel centerline for $300 \mathrm{~V}, 10,20$, and $30 \mathrm{mg} / \mathrm{s}$. 


\section{Axial Electric Field}

The axial electric field, $E_{z}$ was computed from the first derivative of the corrected plasma potential in the axial direction. The results are shown throughout the measurement domain for $300 \mathrm{~V}$ at 10,20 , and $30 \mathrm{mg} / \mathrm{s}$ in the fourth row of Figure $11(300 \mathrm{~V}, 30 \mathrm{mg} / \mathrm{s}$ has single sweep). The peak axial electric field appeared to be weaker and more spread out at $10 \mathrm{mg} / \mathrm{s}$ than at 20 and $30 \mathrm{mg} / \mathrm{s}$. To highlight these differences, the plasma potential is compared on channel centerline in Figure 10 for $300 \mathrm{~V}, 10,20$, and $30 \mathrm{mg} / \mathrm{s}$. The peak axial electric field moved downstream with each addition of anode flow rate, occurring at 95,100 , and $102 \% \mathrm{Lc}$ for 10,20 , and $30 \mathrm{mg} / \mathrm{s}$, respectively. The centerline axial electric field appeared to increase in strength while becoming more compact (same total acceleration occurs) as flow rate was increased. The centerline peak electric field was 37,50 , and $60 \mathrm{~V} / \mathrm{mm}$ at 10, 20, and 30 $\mathrm{mg} / \mathrm{s}$, respectively.

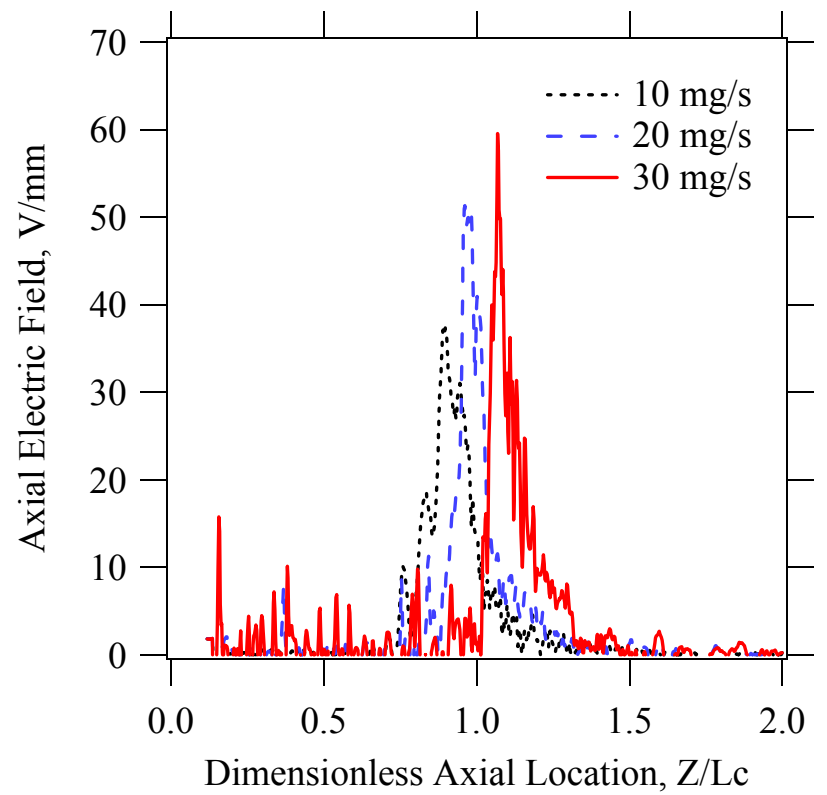

Figure 10. Comparison of axial electric field on channel centerline at $300 \mathrm{~V}, 10,20$, and $30 \mathrm{mg} / \mathrm{s}$.

\section{Radial Electric Field}

The radial electric field was computed from the first derivative of the plasma potential in the radial direction. The magnitude of the radial electric field remained below a few $\mathrm{V} / \mathrm{mm}$, and the structure did not exhibit much cohesion that would lead to useful conclusions. As such, the results for radial electric field have been omitted. However, the low radial electric field was expected since most of the acceleration occurred near the exit plane where the magnetic field lines were primarily radial. The magnetic field lines serve as an estimate of the equipotential lines [20], leading to the result that the plasma potential was highly uniform across the channel. The plasma potential uniformity resulted in very little radial electric field, and hence, negligible radial focusing of the ions toward channel centerline. 


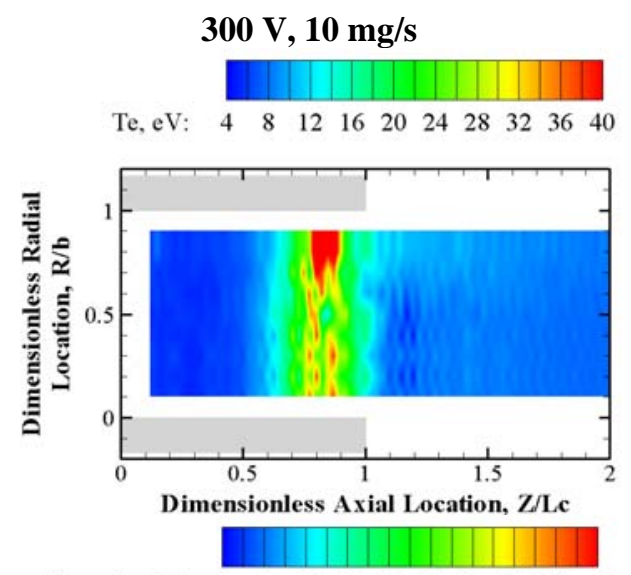

Te_emis, eV: $\begin{array}{llllllllll}4 & 8 & 12 & 16 & 20 & 24 & 28 & 32 & 36 & 40\end{array}$
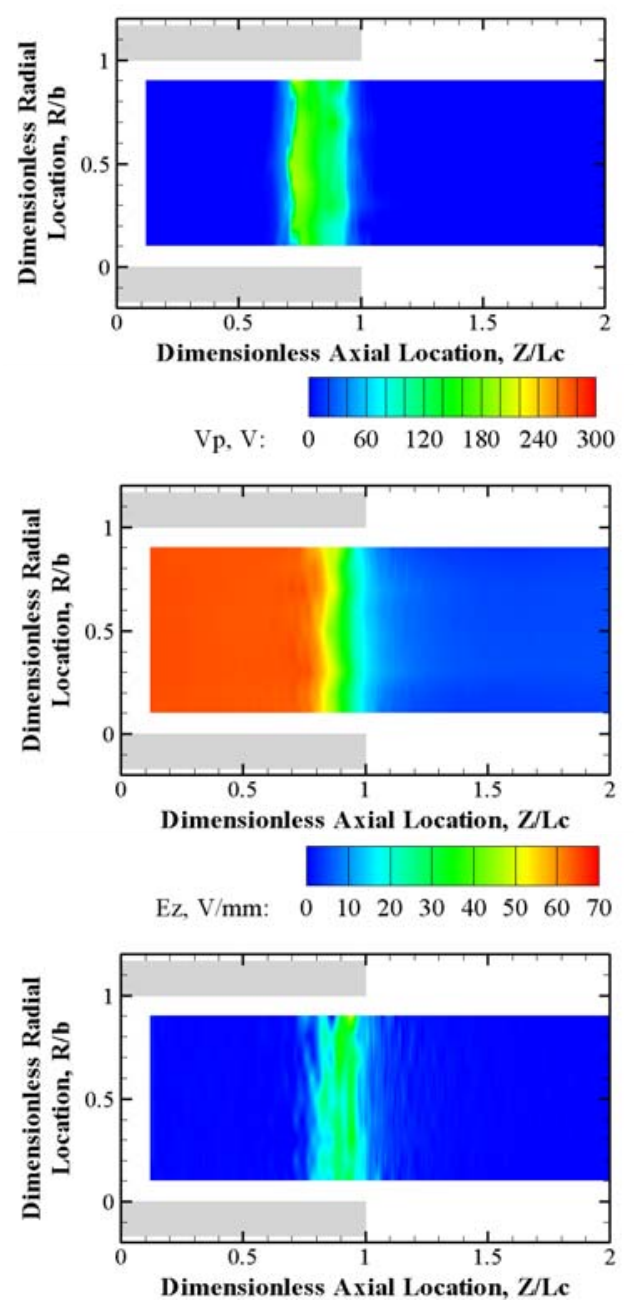

$300 \mathrm{~V}, 20 \mathrm{mg} / \mathrm{s}$

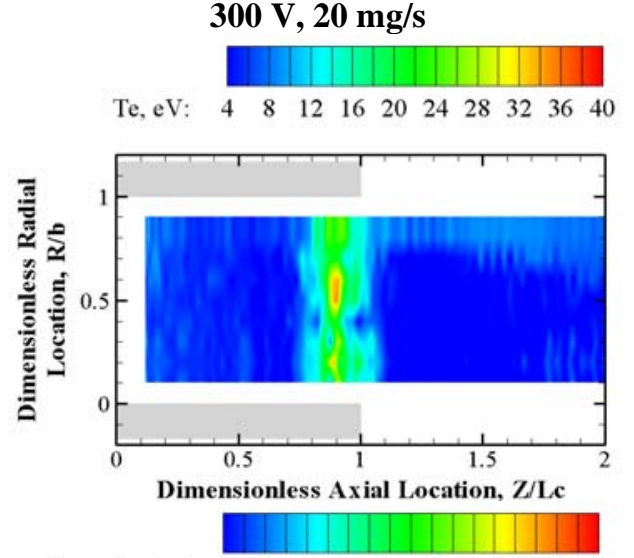

Te_emis, eV: $\begin{array}{llllllllll}4 & 8 & 12 & 16 & 20 & 24 & 28 & 32 & 36 & 40\end{array}$
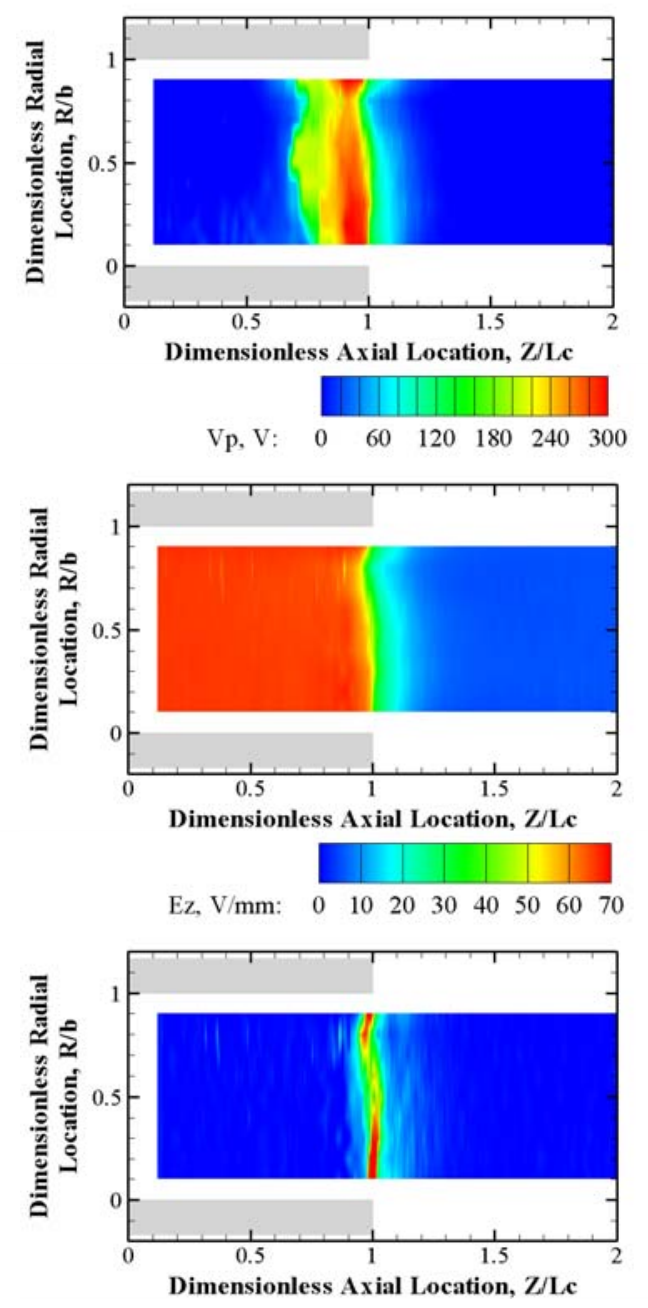

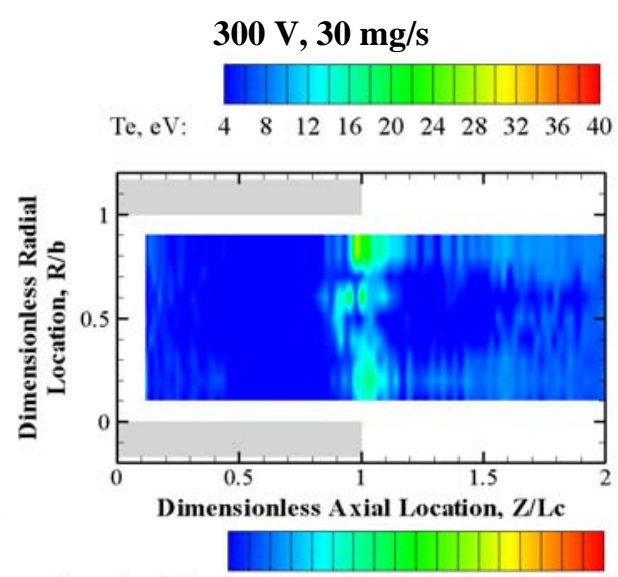

Te_emis, eV: $\begin{array}{llllllllll}4 & 8 & 12 & 16 & 20 & 24 & 28 & 32 & 36 & 40\end{array}$
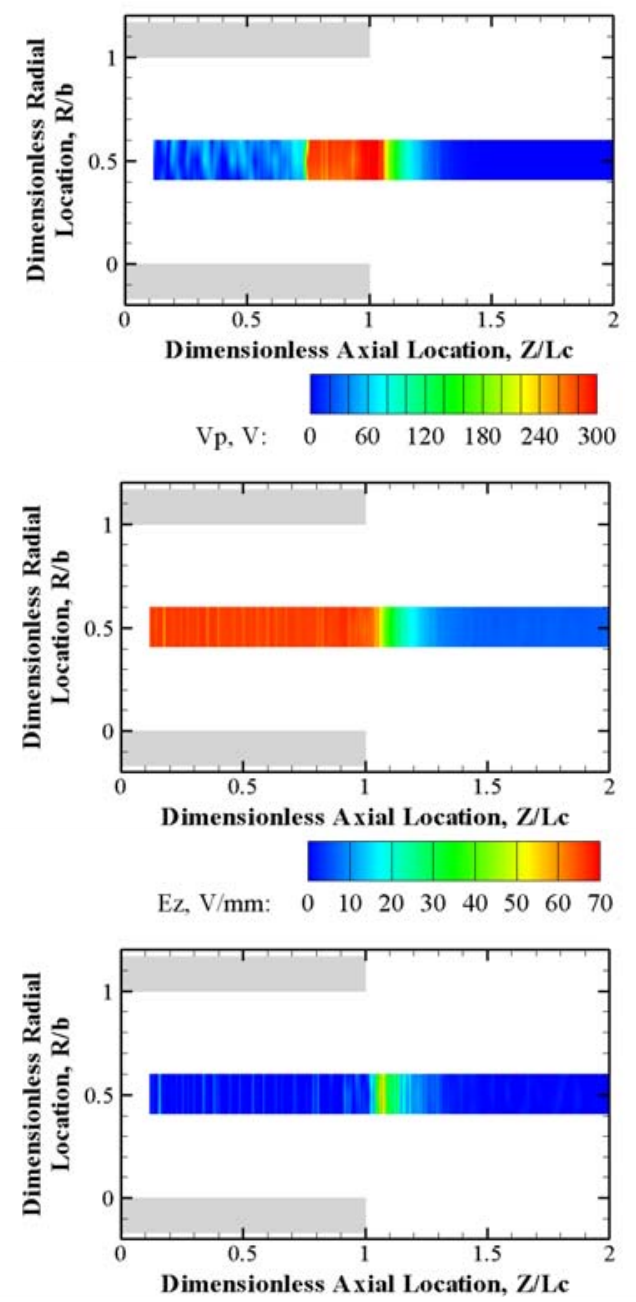

Figure 11. Major results from internal analysis at $300 \mathrm{~V}, 10,20$, and $30 \mathrm{mg} / \mathrm{s}$.

\section{Discussion}

We discuss the trends of electron cooling and peak property displacement downstream with increased mass flow rate. The electron temperature produced by Langmuir and emissive probe methods are compared, and causes for the differences in the acceleration region at different flow rates are suggested. Finally, we compare plasma potential 
results with ion energy measurements from a Retarding Potential Analyzer (RPA). Again, all potentials are with respect to facility ground.

\section{A. Electron Temperature Gradient}

The linear dependence between the electron temperature and plasma potential was recognized by Zharinov et. al [3] and observed by several other experiments [2, 10,21]. The linear dependence between electron temperature and plasma potential is shown in Figure 12 for $300 \mathrm{~V}, 10,20$, and $30 \mathrm{mg} / \mathrm{s}$. The dependence of the electron temperature on the plasma potential was calculated at channel centerline, and the results are summarized in Table 2 for each operating condition. Selected results from Refs. $[2,10,21]$ are also included in Table 2. Although the data were derived from two probe types with three different thrusters operating over a wide range of discharge voltage, anode mass flow rates, and propellant type, the temperature-potential slopes showed good agreement, varying from 0.07 to $0.16 \mathrm{eV} / \mathrm{V}$.
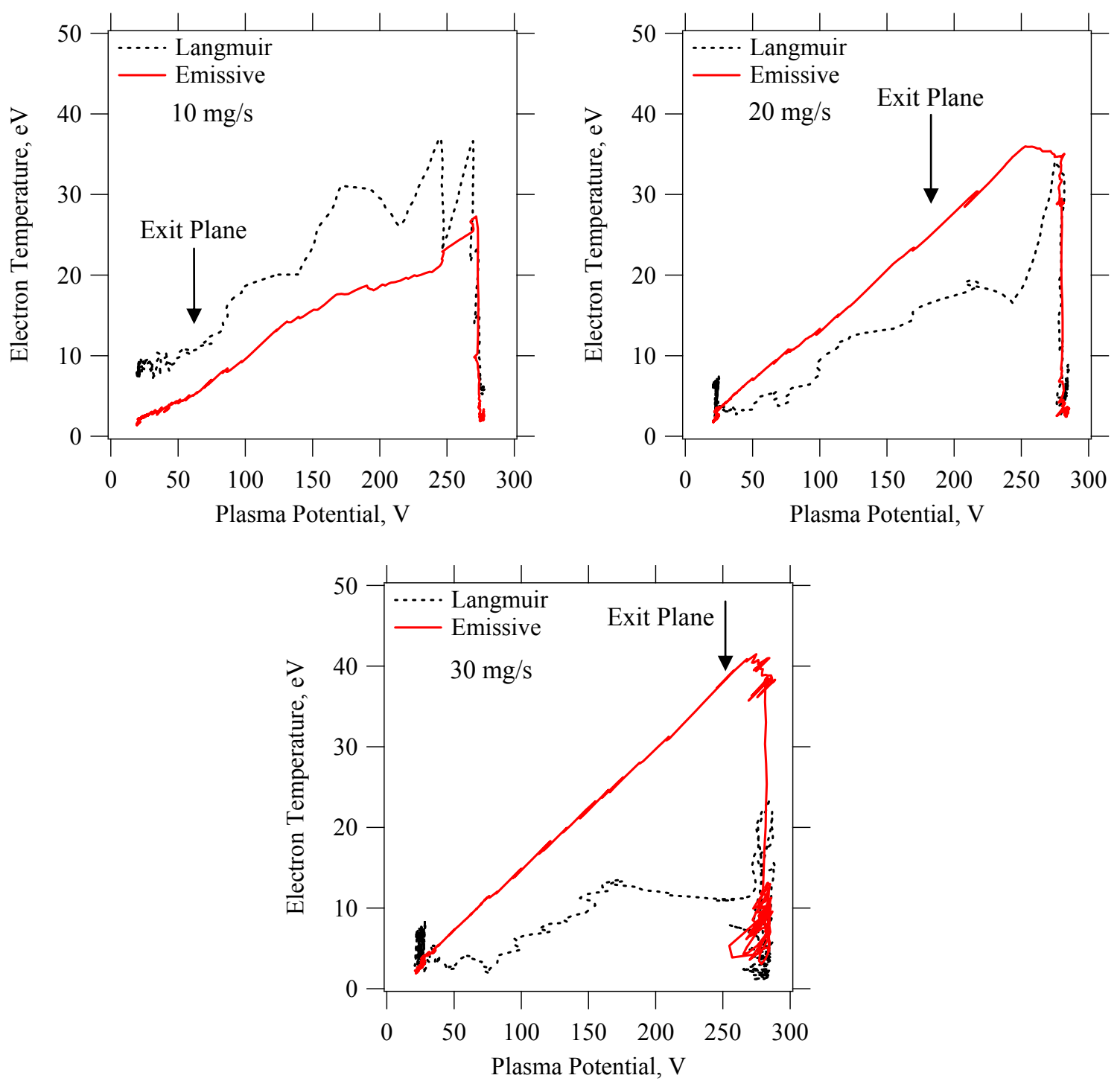

Figure 12. Linear dependence between electron temperature and plasma potential.

The highly linear slope associated with the emissive electron temperature calculation was likely an artifact of the linear dependence of Equation 1 on plasma potential. The Langmuir probe results still followed a similar linear trend, but suffered from significant variability. The Langmuir probe was mostly linear in the near-field plume, but after the probe entered the channel, the slope fell off significantly, especially at $30 \mathrm{mg} / \mathrm{s}$. The near-field linearity was attributed to uniform electron heating from the uniformly increasing electric field, which peaked near the exit plane 
then abruptly decreased. Once inside the channel, there was little electric field heating and the walls tended to cool the electrons due to collisions and near-wall conductivity. The abrupt decrease in electron temperature inside the channel was likely initiated by the electron energy loss due to ionization collisions in the primary ionization zone. The decrease in electron temperature further upstream of the exit was likely due to elevated neutral density that caused increased electron-neutral collisions that increased electron energy losses and enhanced classical mobility in this region of reduced magnetic field.

\section{Table 2. Electron temperature-plasma potential slopes.}

\begin{tabular}{lcc} 
& Emissive Probe & Langmuir Probe \\
\hline \hline Reid [18] 300 V, 10 mg/s & 0.12 & 0.12 \\
Reid [18] 300 V, 20 mg/s & 0.13 & 0.10 \\
Reid [18] 300 V, 30 mg/s & 0.15 & 0.08 \\
\hline Linnell [2] 300 V, $10 \mathrm{mg} / \mathrm{s}-\mathrm{Xe}$ & -- & 0.10 \\
Linnell [2] 500 V, 10 mg/s - Xe & 0.07 & 0.08 \\
Linnell [2] 500 V, 10 mg/s - Kr & 0.10 & 0.08 \\
\hline Raitses [10] 350 V, $1.9 \mathrm{mg} / \mathrm{s}$ & 0.15 & -- \\
Raitses [10] 600 V, $1.9 \mathrm{mg} / \mathrm{s}$ & 0.16 & --
\end{tabular}

The slope of the electron temperature versus plasma potential for the Langmuir probe decreases linearly from $0.12 \mathrm{eV} / \mathrm{V}$ at $10 \mathrm{mg} / \mathrm{s}$ to $0.08 \mathrm{eV} / \mathrm{V}$ at $30 \mathrm{mg} / \mathrm{s}$. This is consistent with the observation of decreased peak electron temperature with flow rate. Conversely, the slope for the emissive probe appears to increase slightly, with slopes of $0.12,0.13$, and 0.15 at 10,20 , and $30 \mathrm{mg} / \mathrm{s}$, respectively. The agreement between the two probes is quite good at 10 $\mathrm{mg} / \mathrm{s}$, with increasingly larger deviations at 20 and $30 \mathrm{mg} / \mathrm{s}$. Larger electron temperature to plasma potential slopes indicate a larger electron energy gain (or lower energy loss) for an applied electric field. This indicates that there are fewer losses at lower flow rate, which is consistent with the hypothesis that neutral cooling moderates the electron temperature as flow rate is increased.

\section{B. Electric Field Distribution}

The variation in shape and strength of the axial electric with increased flow rate is attributed to neutral collision effects. In regions of low neutral density, gradual changes in electric field are expected since electrons can move further before liberating all of their energy. When the density is high, the electron motion is limited since they encounter many collisions over a short distance. For all conditions, the density outside the channel is relatively low due to expected propellant utilizations of approximately $90 \%$ at all conditions. This results in a smeared electric field on the downstream side of the peak electric field location at all operating conditions. At $10 \mathrm{mg} / \mathrm{s}$, the neutral density is relatively low inside the channel, causing symmetric smearing on the upstream and downstream boundaries of the acceleration zone. At $20 \mathrm{mg} / \mathrm{s}$ the density is twice as high inside the channel, causing an asymmetric shape with a somewhat abrupt upstream boundary and smeared downstream boundary. The asymmetric acceleration zone is more pronounced at $30 \mathrm{mg} / \mathrm{s}$ where the further increase in the neutral density in the channel causes a more abrupt upstream boundary.

\section{Peak Plasma Properties}

The approximate magnitude and locations of the peak electron temperature, electric field, and ion number density [18] are shown in Table 3. The locations of the peak properties move downstream with each addition of flow rate. The peak OML ion density coincides with the peak Te at all flow rates, and the peak electric field is $7-10 \% \mathrm{Lc}$ downstream. These trends indicate that the ionization and acceleration mechanisms are linked together and move downstream as a group as flow rate is increased. These properties are likely pushed downstream with increased flow rate by the increased collision rate that reduces the likelihood that electrons will be transported toward the anode. These electrons are forced to organize further downstream, requiring a higher electric field to sustain the cross-field mobility necessary to maintain the discharge. The higher electric field can also be viewed as the necessary component to compensate for the increase in the effective plasma resistance that is imposed by the increased magnetic field. These factors contribute to the observation of more compact acceleration zones at 20 and $30 \mathrm{mg} / \mathrm{s}$. 
Table 3. Approximate magnitude and location of peak plasma properties. Ion number densities and peak locations are taken from Ref. [18].

\begin{tabular}{cccc} 
Peak Property Magnitude & $10 \mathrm{mg} / \mathrm{s}$ & $20 \mathrm{mg} / \mathrm{s}$ & $30 \mathrm{mg} / \mathrm{s}$ \\
\hline \hline $\mathrm{T}_{\mathrm{e}}, \mathrm{eV}$ & 42 & 36 & 25 \\
$\mathrm{~T}_{\mathrm{e}}, \mathrm{eV}$ - emissive & 28 & 40 & 45 \\
$\mathrm{E}_{\mathrm{z}}, \mathrm{V} / \mathrm{mm}$ & 42 & 78 & 62 \\
$\mathrm{n}_{\mathrm{i}, \mathrm{OML}}, \mathrm{x} 18 \mathrm{~m}^{-3}$ & 2 & 4 & 9 \\
$\mathrm{n}_{\mathrm{i}, \text { thin, }}, \mathrm{x} 18 \mathrm{~m}^{-3}$ & 1 & 4 & 15 \\
Peak Property Location, \% Lc & & & \\
\hline \hline $\mathrm{T}_{\mathrm{e}}$ & 86 & 90 & 98 \\
$\mathrm{E}_{\mathrm{z}}$ & 93 & 100 & 107 \\
$\mathrm{~T}_{\mathrm{e}}$ & 79 & 90 & 93 \\
$\mathrm{n}_{\mathrm{i}, \mathrm{OML}}$ & 86 & 90 & 98 \\
$\mathrm{n}_{\mathrm{i}, \text { hin }}$ & 86 & 74 & 79
\end{tabular}

\section{Consistency with Retarding Potential Analyzer}

Plasma potential measurements from the floating emissive probe are compared to ion energy measurements from a RPA and the measured anode potential in Figure 13a for $300 \mathrm{~V}, 10,20$, and $30 \mathrm{mg} / \mathrm{s}$. The ion velocity distribution was measured with the RPA positioned $2 \mathrm{~m}$ from the exit plane. The raw RPA potential increased by $1-2 \mathrm{~V}$ for each addition of $10 \mathrm{mg} / \mathrm{s}$, and the RPA potential corrected by the local plasma potential remained constant to within $0.5 \%$. The corrected RPA potential was within $10 \%$ of the anode potential at all operating conditions, indicating nearly constant voltage utilization efficiency $\left(\eta_{\mathrm{v}}=\mathrm{V}_{\text {accel }} / \mathrm{V}_{\mathrm{d}}\right)$. The plasma potential measured by the emissive probe was within $3.8,1.4$, and $2.0 \%$ of the anode potential at 10,20 , and $30 \mathrm{mg} / \mathrm{s}$, respectively. The estimated uncertainty in the plasma potential near the anode was $\pm 10 \mathrm{~V}$ since the voltage drop across the filament was approximately $10 \mathrm{~V}$ and the electron temperature was approximately $5 \mathrm{eV}$ (uncertainty of $0.9 T_{e}$ ). Considering the uncertainty, the peak plasma potential at each operating condition was consistent with the anode potential and RPA measurements.
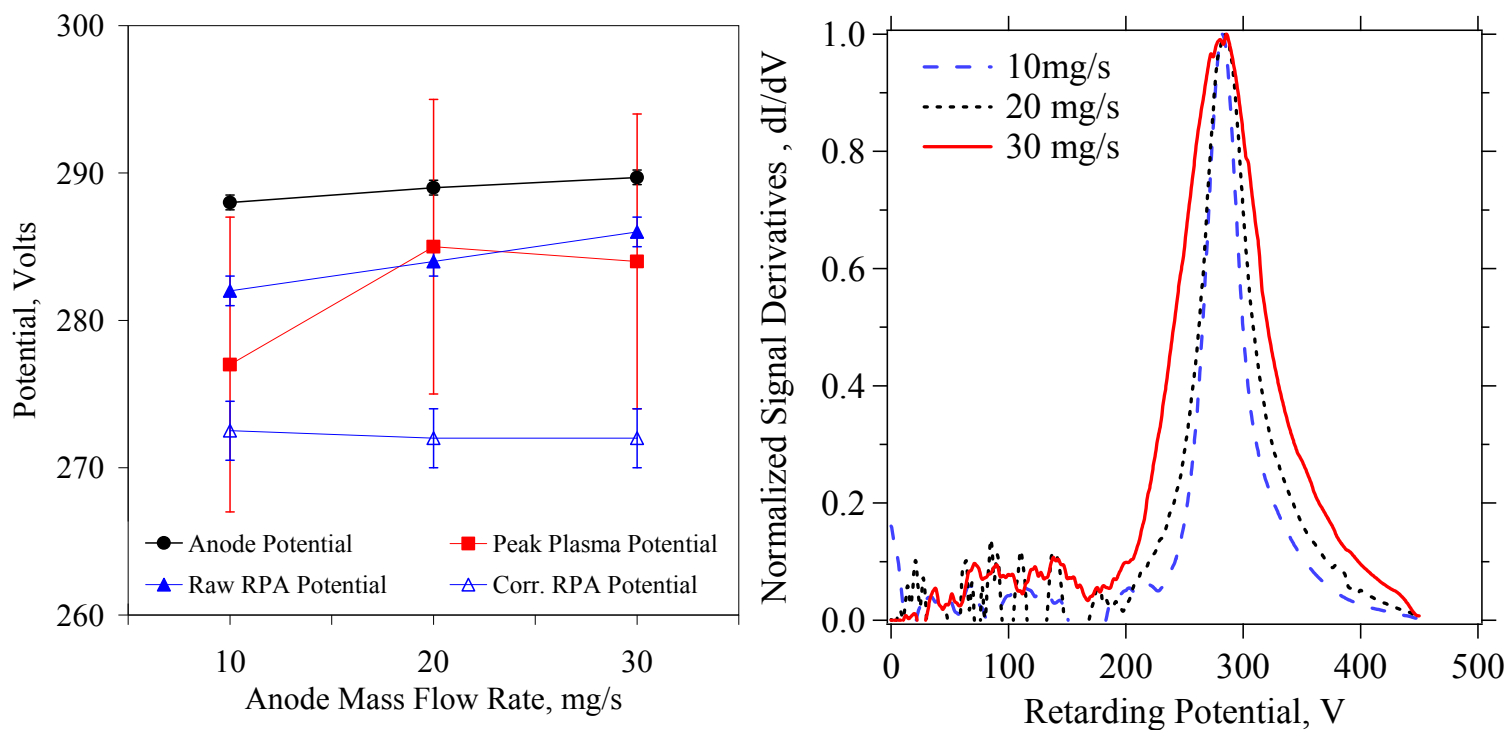

Figure 13. a) Comparison of RPA measurements and b) comparison of anode potential, plasma potential, and $R P A$ results for $300 \mathrm{~V}$ at 10,20 , and $30 \mathrm{mg} / \mathrm{s}$.

The ion velocity distributions were relatively symmetric about the most probable voltage at each flow rate as shown in Figure 13. The FWHM was measured as 34, 46, and $80 \mathrm{~V}$ at 10, 20, and $30 \mathrm{mg} / \mathrm{s}$, respectively. A similar trend of increasing signal broadening with anode flow rate was measured with an $\mathrm{E} \times \mathrm{B}$ probe in a separate experiment [22]. 


\section{Conclusion}

Plasma potential measurements were taken at a discharge voltage of $300 \mathrm{~V}$ and anode flow rates of 10, 20, and $30 \mathrm{mg} / \mathrm{s}$ using a floating emissive probe. The cathode flow fraction and magnetic field topology were held constant, and the magnetic field strength was varied to minimize discharge current while maximizing thrust.

The peak electron temperature was found to decrease with increased flow rate, peaking at approximately 38,35 , and $25 \mathrm{eV}$ at 10,20 , and $30 \mathrm{mg} / \mathrm{s}$. The trend was attributed to increased electron loss mechanisms including increased electron-neutral collisions and wall collisions. The electron temperature calculated by the emissive probe did not match this trend, instead displaying an increase in electron temperature with increased flow rate.

The electron temperature calculated from an emissive probe varied linearly with plasma potential, likely a result of the linear dependence on plasma potential in Equation 1. The electron temperature calculated from a Langmuir probe also displayed a linear dependence on plasma potential outside the channel. The slope of the Langmuir probe temperature with plasma potential decreased with flow rate, consistent with the hypothesis of electron cooling through neutral collisions.

Based on these results, it appeared that neutral collision effects contributed considerably to the shape, location, and magnitude of the peak plasma properties including axial electric field, electron temperature, and ion density. Over the wide range of discharge powers $(3-10 \mathrm{~kW})$, the results showed that the location of the peak ion density, electron temperature, and axial electric field all moved downstream with increased flow rate. The axial electric field was negligible throughout most of the channel and displayed a strong peak near the exit plane. The location of peak electron temperature and ion density coincided [18] and were located a 3-5\% Lc upstream of the peak axial electric field at each operating condition. The whole assembly of properties moved downstream 3-5\% Lc for each $10 \mathrm{mg} / \mathrm{s}$ increase in anode flow rate.

\section{Acknowledgments}

The authors would like to thank Mr. Michael McDonald and Mr. Rohit Shastry for their assistance with the experimental setup and data acquisition. Mr. Terry Larrow provided invaluable help in producing several prototype probe components. We would also like to recognize Dr. Jesse Linnell for his many fruitful discussions and suggestions. The first author has been supported throughout his graduate studies by the NASA Michigan Space Grant Consortium Fellowship, NASA Harriett Jenkins Pre-doctoral Fellowship Program, and the University of Michigan Rackham Merit Fellowship. The authors would like to acknowledge and thank the Air Force Office of Scientific Research (AFOSR) for funding this research. Dr. Mitat Birkan is the Project Manager for Grant FA955006-1-0105.

\section{References}

[1] Haas, J. M., "Low-Perturbation Interrogation of the Internal and near-Field Plasma Structure of a Hall Thruster Using a High-Speed Probe Positioning System," Ph.D. Dissertation, Dept. of Aerospace Engineering, University of Michigan, 2001.

[2] Linnell, J. A., "An Evaluation of Krypton Propellant in Hall Thrusters," Ph.D. Dissertation, Dept. of Aerospace Engineering, University of Michigan, Ann Arbor, 2007.

[3] Zharinov, A. V. and Popov, Y. S., "Acceleration of Plasma by a Closed Hall Current (Physical Aspects of Plasma Accelerator Using Closed Hall Currents, Discussing Equilibrium of Forces and Potential Distribution)," Soviet Physics. Technical Physics, 12, 208, 1967.

[4] Haas, J. M., Hofer, R. R., Brown, D. L., Reid, B. M. and Gallimore, A. D., "Design of the \#\# Hall Thruster for High Thrust/Power Investigation," Presented at the 54th JANNAF Propulsion Meeting, Denver, CO, May 14-17, 2007.

[5] Reid, B. M., Gallimore, A. D., Hofer, R. R., Li, Y. and Haas, J. M., "Anode Design and Verification for the \#\# Hall Thruster," Presented at the 54th JANNAF Propulsion Meeting, Denver, CO, May 14-17, 2007.

[6] Hofer, R. R., Goebel, D. M. and Watkins, R. M., "Compact LaB6 Hollow Cathode for the \#\# Hall Thruster," Presented at the 54th JANNAF Propulsion Meeting, Denver, CO, May 14-17, 2007.

[7] Brown, D. L., Reid, B. M., Gallimore, A. D., Hofer, R. R., Haas, J. M., et al., "Performance Characterization and Design Verification of the \#\# Laboratory Model Hall Thruster," Presented at the 54th JANNAF Propulsion Meeting, Denver, CO, May 14-17, 2007.

[8] Dymond, J. H. and Smith, E. B., The Virial Coefficients of Pure Gases and Mixtures, a Critical Compilation, Oxford University Press, New York, 1980. 
[9] Haas, J. M., Gallimore, A. D., McFall, K. and Spanjers, G., "Development of a High-Speed, Reciprocating Electrostatic Probe System for Hall Thruster Interrogation," Review of Scientific Instruments, 71, 11, 4131-4138, 2000.

[10] Raitses, Y., Staack, D., Smirnov, A. and Fisch, N. J., "Space Charge Saturated Sheath Regime and Electron Temperature Saturation in Hall Thrusters," Physics of Plasmas, 12, 073507, 2005.

[11] Raitses, Y., Staack, D. and Fisch, N. J., "Plasma Characterization of Hall Thruster with Active and Passive Segmented Electrodes," AIAA Journal, 2002-3954, 2002.

[12] Hargus, W. A. and Cappelli, M. A., "Interior and Exterior Laser-Induced Fluoresence and Plasma Measurements with a Hall Thruster," Journal of Propulsion and Power, 18, 1, 159-168, 2002.

[13] Chen, F. F. "Electric Probes." Plasma Diagnostic Techniques, R. H. Huddlestone and S. L. Leonard, eds., Academic Press, New York. 1965.

[14] Hobbs, G. D. and Wesson, J. A., "Heat Flow through a Langmuir Sheath in the Presence of Electron Emission," Plasma Physics, 9, 1, 85-87, 1967.

[15] Schwager, L. A., Hsu, W. L. and Tung, D. M., "Effects of Cold Electron Emission on the Plasma Sheath," Physics of Fluids B: Plasma Physics, 5, 2, 621-630, 1993.

[16] Linnell, J. A. and Gallimore, A. D., "Internal Plasma Potential Measurements of a Hall Thruster Using Plasma Lens Focusing," Physics of Plasmas, 13, 103504, 2006.

[17] Haas, J. M. and Gallimore, A. D., "Internal Plasma Potential Profiles in a Laboratory-Model Hall Thruster," Physics of Plasmas, 8, 2, 652-660, 2001.

[18] Reid, B. M. and Gallimore, A. D., "Langmuir Probe Measurements in the Discharge Channel of a 6-kW Hall Thruster," 44th AIAA/ASME/SAE/ASEE Joint Propulsion Conference, AIAA-2008-4920, Hartford, CT, Jul. 20-23, 2008.

[19] Cherrington, B. E., "The Use of Electrostatic Probes for Plasma Diagnostics - a Review," Plasma Chemistry and Plasma Processing, 2, 2, 113-140, 1982.

[20] Zhurin, V. V., Kaufman, H. R. and Robinson, R. S., "Physics of Closed Drift Thrusters," Plasma Sources Science and Technology, 8, 1, R1-R20, 1999.

[21] Staack, D., Raitses, Y. and Fisch, N. J., "Temperature Gradient in Hall Thrusters," Applied Physics Letters, 84, 16, 3028-3030, 2004.

[22] Reid, B. M., Shastry, R., Gallimore, A. D. and Hofer, R. R., "Angularly-Resolved ExB Probe Spectra in the Plume of a 6-kW Hall Thruster," 44th AIAA/ASME/SAE/ASEE Joint Propulsion Conference, AIAA-2008-5287, Hartford, CT, Jul. 20-23, 2008. 